\title{
A non-linear beta-binomial regression model for mapping qlqc-30 to the eq-5d in lung cancer patients: a comparison with existing approaches
}

\author{
Iftekhar Khan ${ }^{\text {* }}$, Shah-Jalal Sarker ${ }^{2}$, Steven Morris ${ }^{1}$ \\ From 2nd Clinical Trials Methodology Conference: Methodology Matters \\ Edinburgh, UK. 18-19 November 2013
}

\section{Background}

The performance of the Beta Binomial (BB) model is compared with several existing models for mapping the QLQC-30 on to the EQ-5D using data from lung cancer trials.

\section{Methods}

Data from 2 separate non-small cell lung cancer clinical trials (TOPICAL and SOCCAR) are used to develop and validate the $\mathrm{BB}$ model. Comparisons with Linear, TOBIT, Quantile, Quadratic and CLAD models were carried out. The mean prediction error, $\mathrm{R}^{2}$, proportion predicted outside the valid range, clinical interpretation of coefficients, model fit and estimation of Quality Adjusted Life Years (QALY) are reported and compared. Monte-Carlo simulation from mixture distributions was performed to assess the performance of the models.

\section{Results}

The Beta-Binomial regression model performed 'best' among all models. Estimates from the BB were more accurate for predicting EQ-5D and QALYs compared to other modelling approaches. Mean difference in QALYs (predicted vs. observed) were 0.053 vs. 0.051 for TOPICAL and 0.162 vs. 0.164 for SOCCAR. Simulated 95\% confidence intervals showed that the BB model contained the observed mean more often compared to the other models. All algorithms over-predict at poorer health states but the BB model was relatively better, particularly for the SOCCAR data.

${ }^{1}$ University College London, London, UK

Full list of author information is available at the end of the article

\section{Conclusion}

The Beta Binomial regression may offer superior predictive properties compared to existing algorithms and could be a more appropriate algorithm to map the relationship between the EQ-5D and QLQC-30. Future models could include toxicity data jointly with EQ-5D to improve prediction at poorer health states. The generalized lambda distribution may offer a way to simulate from a mixture distribution.

\section{Authors' details}

${ }^{1}$ University College London, London, UK. ${ }^{2}$ University of London - Queen Mary, London, UK.

Published: 29 November 2013

doi:10.1186/1745-6215-14-S1-O23

Cite this article as: Khan et al:: A non-linear beta-binomial regression model for mapping qlqc-30 to the eq-5d in lung cancer patients: a comparison with existing approaches. Trials 2013 14(Suppl 1):O23.

Submit your next manuscript to BioMed Central and take full advantage of:

- Convenient online submission

- Thorough peer review

- No space constraints or color figure charges

- Immediate publication on acceptance

- Inclusion in PubMed, CAS, Scopus and Google Scholar

- Research which is freely available for redistribution 